\title{
A HISTÓRICA ESTÂNCIA DE SANTIAGO, EM SAINT-HILAIRE E OUTROS CLÁSSICOS DA LITERATURA SULINA
}

\author{
JOSÉ NEWTON CARDOSO MARCHIORI ${ }^{1}$ FABIANO DA SILVA ALVES $^{2}$
}

\section{RESUMO}

Prova-se, com base na literatura, que o botânico francês Auguste de Saint-Hilaire nunca esteve em terras do atual município de Santiago e que a capela jesuítica de mesmo nome foi erigida entre os rios Jaguari e Toropi.

Palavras-chave: Saint-Hilaire, Santiago, Jarí, Rio Grande do Sul.

\section{SUMMARY}

[The historic Santiago ranch according to Saint-Hilaire and other classics of southern brazilian literature].

Based on literature, this paper proves that the french botanist Auguste de Saint-Hilaire never crossed by the municipality of Santiago, Rio Grande do Sul state (Brazil), and the jesuitic chapel of the same name was also erected on land situated between Jaguari and Toropi rivers.

Key words: Saint Hilaire, municipality of Santiago, municipality of Jarí, Rio Grande do Sul state, Brazil.

\section{INTRODUÇÃO}

Inúmeros artigos e, até mesmo, livros sobre as origens da cidade de Santiago repetem uma informação equivocada, que não resiste à luz da documentação histórica: a pretensa vinculação de suas origens com a Capela de São Tiago, erigida na estância jesuítica de mesmo nome, pertencente ao povo missioneiro de São Miguel. A bem da justiça, cabe salientar que Hemetério José Velloso da Silveira, meticuloso cronista do início do Século XX, não cometeu esta falha em sua conhecida obra ${ }^{3}$, no capítulo relativo a "São Thiago do Boqueirão".

Outro erro, exaustivamente repetido, diz respeito à passagem de Saint-Hilaire por Santiago a 30 de março de 1821 , ou pelas

1 Engenheiro Florestal, Dr. Professor Titular do Departamento de Ciências Florestais, UFSM. Bolsista de Produtividade em Pesquisa (CNPq - Brasil).

2 Biólogo, MSc. Doutorando do Programa de Pós-Graduação em Engenharia Florestal, UFSM. Professor da Universidade da Região da Campanha-URCAMP (Alegrete, RS).

3 SILVEIRA, H.J.V. da. As Missões Orientais e seus antigos domínios. Porto Alegre: Typographia da Livraria Universal de Carlos Echenique, 1909. p. 463-468. localidades de Florida e Quatro Bocas, no interior do mesmo município ${ }^{4}$.

Em ambos os casos, a confusão é mais recente e se deve a uma leitura descuidada, senão tendenciosa, da "Viagem" de Auguste de SaintHilaire $^{5}$ ao Rio Grande do Sul ${ }^{6}$.

4 Antero Simões, em "Santiago, sua terra, sua gente", é um dos autores que refere, textualmente, a passagem do sábio francês por Santiago na referida data (SIMÕES, A. Op. cit., p. 15), um flagrante absurdo, demonstrado a seguir. Embora desposando a mesma tese, Guirahy Pozo manifestou estranheza pelo fato do francês ter levado apenas "dois dias de carroça", entre Tupanciretã e Santiago (POZO, G. Op. cit., p. 8). Mesmo sem vincular o nome da cidade ao antigo morador (Santiago) referido por Saint-Hilaire, Núncia S. de Constantino tangenciou a questão, dizendo que a hipótese "não pode ser aceita sem desconfiança" (CONSTANTINO, N. S. de. Op. cit., p. 28-29); o presente trabalho visa, justamente, a demonstrar tal impossibilidade, pelas simples razões de que o botânico francês nunca pisou em terras do atual município de Santiago e que o morador de mesmo nome, referido pelo naturalista, se é que existiu, vivia, certamente, em terras do atual município de Jari.

5 Natural de Orléans, França (4/10/1779), AugustinFrançois-César Prouvençal de Saint-Hilaire, mais conhecido como Auguste de Saint-Hilaire, já era um distinguido pesquisador do Museu de História Natural de Paris quando chegou ao Brasil em 1816, junto com o Duque de Luxemburgo, recém nomeado ministro francês no Rio de Janeiro. O texto da "viagem" cobre o pe- 


\section{ANÁLISE CRÍTICA DE ANTIGOS TEXTOS}

Observador atento da terra e da gente gaúcha, o diário do botânico francês é documento de real valor sob muitos pontos de vista e geralmente digno de confiança, por ser isento de parcialidade, com a possível exceção de alguns juízos sobre temas de natureza política, caso muito distinto, portanto, do que nos cabe analisar.

Em seu deslocamento de Santo Ângelo a Santa Maria, Saint-Hilaire passou, efetivamente, por uma "Estância de Santiago", a 30 de março de 1821 . A respeito do local, o viajante deixou poucas anotações de interesse ao presente caso, informando, todavia, que ali habitava um "brasileiro que morava para os lados de Quaraim" e que o local fora anteriormente ocupado por um "espanhol", do qual derivaria o nome da estância (Santiago) ${ }^{7}$. Tais referências aos habitantes carecem de maior interesse no presente artigo, até mesmo porque o eventual esclarecimento desse ponto em nada serve para elucidar a questão em foco.

De todo modo, o "Santiago" anotado por Saint-Hilaire nada tem a ver com o "Boqueirão do Santiago" ou "Boqueirão de Santiago" referidos por Arsène Isabelle e constantes nas traduções de sua obra, feitas por Dante de Laytano $^{8}$ e Theodomiro Tostes ${ }^{9}$, respectivamente. Este "boqueirão", posicionado por Isabelle a "mais ou menos treze léguas" a

ríodo de 4 de junho de 1820 a 24 de junho de 1821 , incluindo o tempo em que o francês esteve na Província Cisplatina (atual Uruguai).

6 Das várias edições deste verdadeiro clássico da literatura sulina, as referências a seguir baseiam-se no texto traduzido por Adroaldo Mesquita da Costa, editado pela ERUS, em co-edição com Martins Livreiro: SAINTHILAIRE, A. de. Viagem ao Rio Grande do Sul. Porto Alegre: Estante Rio-Grandense União de Seguros ERUS; Martins Livreiro, 1987. 496 p.

7 SAINT-HILAIRE, 1987. Op. cit., p. 322.

8 ISABELLE, A. Viagem ao Rio Grande do Sul (1833 1834). Porto Alegre: Museu “Julio de Castilhos", secção do Arquivo Histórico, 1946. p. 21.

9 ISABELLE, A. Viagem ao Rio da Prata e ao Rio Grande do Sul. Rio de Janeiro: Livraria Editora Zelio Valverde S,A., 1949. p. 232. "sudeste do Iguariaçá" e descrito como tendo "três ou quatro chácaras e estâncias à entrada de um vale arborizado, onde corria um límpido regato", ele, sim, encontra-se, efetivamente, em terreno condizente com a moderna cidade de Santiago, mas não o referido por Saint-Hilaire.

A origem do nome da moderna cidade gaúcha, em outras palavras, deve ser buscada em outra fonte, pela simples razão de que SaintHilaire nunca cruzou por terras do município de Santiago. Basta ler-se com um mínimo de atenção: dois dias antes ( 28 de março), ele esteve na "Estância de Tupaceretã", após ter cruzado o rio Jaguari, definido como "pequeno", bastante "rápido" e "extremamente piscoso", correndo "sobre leito de rochas", 10 .

Não restam dúvidas: Saint-Hilaire esteve, mesmo, foi em terra dos atual município de Tupanciretã e cruzou o rio Jaguari de sua margem direita para a esquerda, em região não muito distante da nascente. $\mathrm{O}$ trajeto percorrido desde as Missões foi o mais lógico e usual para a época: buscando a proximidade do divisor de águas entre as bacias do Uruguai e Jacuí, esta rota, embora descrevendo um arco, evitava a travessia de rios caudalosos, obstáculo da maior importância naquele tempo, em que os caminhos eram simples trilhas desprovidas de obras-dearte.

A respeito da "Estância de Santiago", cuja designação estaria ligada ao nome de um antigo morador "espanhol", segundo informação repassada por Saint Hilaire ${ }^{11}$, pode-se especular, com segurança, que o termo se prende à estância missioneira de mesmo nome, pertencente ao povo de São Miguel e que compreendia os "postos de São Joaquim, São Clemente, São José Tubichá, São Diogo e outros", segundo Aurélio Porto $^{12}$. Como reforço a esta tese, são bem conhecidos, no município de Jarí, os arroios

\footnotetext{
${ }^{10}$ SAINT-HILAIRE, 1987. Op. cit., p. 322.

${ }^{11}$ SAINT-HILAIRE, 1987. Op. cit., p. 322.

${ }^{12}$ PORTO, A. História das Missões Orientais do Uruguai. Porto Alegre: Livraria Selbach, 1954. v. 1. p. 330.
} 
Santiago, Santana, São Diogo, São José Tujá ${ }^{13}$ e Santo Inácio, afluentes da margem esquerda do rio Jaguari e que remetem ao nome de antigos postos missioneiros da referida Estância de Santiago (Figura 1).

A 31 de março, Saint-Hilaire já escrevia seu diário na "Estância de Salvador Lopes", distante duas léguas da "Estância de Santiago". A $1^{\circ}$ de abril, ele se encontrava na "entrada do mato", após uma jornada de três léguas. No dia seguinte ( 2 de abril), as anotações referem-se a "São Xavier", situada a duas léguas e meia do pouso anterior. Em 3 de abril ele já estava no "ToropiChico", com duas léguas e meia de percurso e, a 4 de abril, nas margens do "Toropi-Grande", distante uma légua e meia do "Toropi-Chico"14.

$O$ diário do viajante não pode ser mais claro: a partir da "Estância de Tupanciretã", o francês seguiu pelo planalto compreendido entre os rios Jaguari e Toropi, alcançando a Depressão Central pela "Picada de São Tiago" ${ }^{15}$. O próprio Saint-Hilaire comentou que para transpor a Serra Geral não havia "senão esse caminho e o da Serra de São Martinho, há muito abandonado"16.

Cabe observar que o viajante francês refere uma única passagem pelo rio Jaguari. Se ele tivesse andado pelos arredores do atual sítio urbano de Santiago ou, até mesmo, se ele tivesse adentrado em terras do mesmo município, o viajante francês deveria ter cruzado, necessariamente, outras duas vezes pelo mesmo rio, fato não relatado em sua minuciosa obra.

Erigida na estância jesuítica de mesmo nome, a Capela de São Tiago já não existia ao tempo da visita do botânico francês, mas não distava, certamente, do local por ele visitado em 30 de

\footnotetext{
${ }^{13}$ Tubichá, segundo grafia de Aurélio Porto.

${ }^{14}$ SAINT-HILAIRE, A. de. Op. cit., p. 323-328.

${ }^{15}$ Designação utilizada por José de Saldanha (SALDANHA, J. de. Diário Resumido e Histórico. Anais da Biblioteca Nacional, Rio de Janeiro, v. 51, 1938, p. 293). O historiador Southey chama essa mesma passagem de "desfiladeiro de Santiago" (SOUTHEY, R. História do Brasil. São Paulo: Ed. Itatiaia; Ed. da Universidade de São Paulo, 1981. v. 3. p. 269).

${ }^{16}$ SAINT-HILAIRE, A. de. Op. cit., p. 325.
}

março de1821. Levantada em terras do atual município de Jarí, nas proximidades da nascente do arroio Santiago (Figura 1), a extinta capela é mencionada em textos de cronistas ainda mais antigos.

$\mathrm{O}$ desconhecimento popular sobre a origem toponímica é fato perfeitamente compreensível ao tempo de Saint-Hilaire. O que não se pode entender, neste caso, é a confusão que ainda hoje teima em persistir, posicionando a referida capela jesuítica em terras do município de Santiago.

De grande valia -e anterior a Saint-Hilaire -é o famoso Diário Resumido e Histórico, firmado no "Acampamento geral do Monte Grande" (atual Santa Maria) por Sebastião Xavier da Veiga Cabral da Câmara e por José de Saldanha, em 10 de novembro de 1787. De início, cabe frisar que o referido diário, além de documento geográfico de valor indiscutível, também encerra valiosas contribuições etnográficas, históricas e para as ciências naturais.

Em suas andanças pela região do Monte $\mathrm{Grande}^{17}$, a equipe responsável pela demarcação de limites entre Portugal e Espanha ${ }^{18}$ passou pela "Estancia de São Pedro", situada "ao Sul da Serra", em 25 de março de 1787, indo acampar no dia 29 "junto aos ranchos do Posto de São João", situado no "Albardão Grande", uma região de "excellentes collinas", compreendida entre o Toropi e o "Yaguari", por onde passa a "estrada geral de carretas para as Missoens" ${ }^{19}$. Vê-se, portanto, que a equipe seguiu a mesma rota usada por Saint-Hilaire, porém em sentido inverso. Cabe salientar que os próprios autores do Diário Resumido esclarecem o significado de albardão, em nota

\footnotetext{
${ }^{17}$ Nome utilizado pelos espanhóis para designar o talude da Serra Geral, revestido por espessas florestas (Monte, em espanhol). A Serra Geral também figura em antigos documentos com o nome de "Serra dos Tapes".

${ }^{18}$ A comissão demarcadora visava a estabelecer o limite entre as terras das duas cortes ibéricas na América, acordado pelo Tratado de Santo Ildefonso (1-10-1777).

${ }^{19}$ SALDANHA, J. de. Op. cit., p. 288.
} 


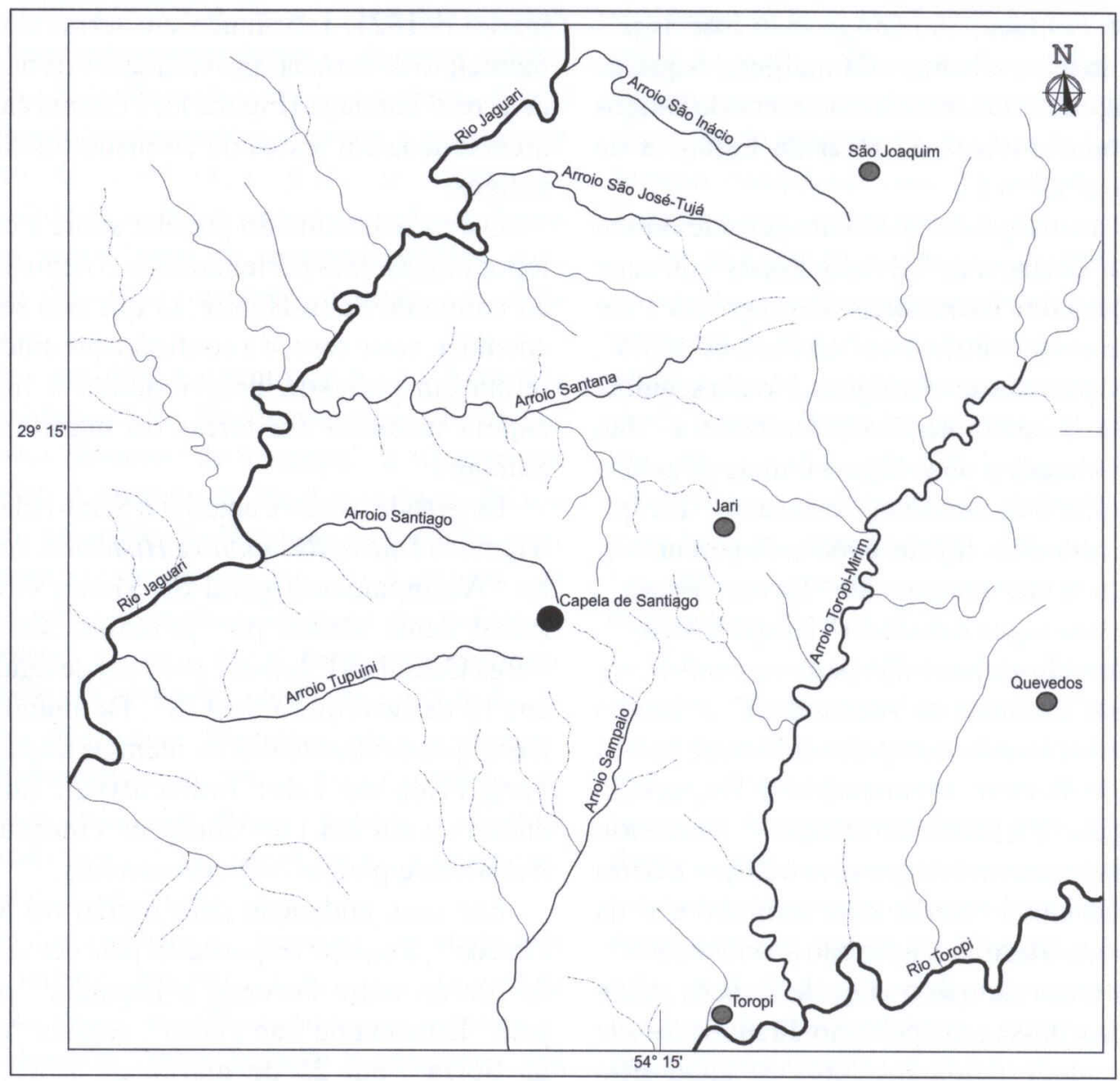

FIGURA 1 - Provável localização da extinta Capela de Santiago.

de rodapé: "Lombo mais elevado, ou seguido do terreno, e que separa as cahidas das agoas para diferentes bandas" ${ }^{20}$.

Seguindo pelo albardão, a equipe de militares e geógrafos passou pelo antigo "Posto de São Joaquim", indo acampar "ao pé da Estancia de S. Tiago" a 3 de maio de $1787^{21}$. Situadas sobre "huma bella collina", as "cazas da Estancia de S. Tiago" ainda tinham, "segundo o costume, o seu Capão de Pessegueiros" 22 .

O Diário Resumido e Histórico não deixa margem a dúvidas: "He perfeitamente fechada

${ }^{20}$ SALDANHA, J. de. Op. cit., p. 168.

${ }^{21}$ Pelo texto de Saldanha, fica-se sabendo que o Posto de São Joaquim, pertencente à Estância de Santiago, ficava ao sul de sua sede (Capela de Santiago).

${ }^{22}$ SALDANHA, J. de. Op. cit., p. 292 esta Estancia de S. Tiago do tamanho de algumas oito Legoas de comprido, e quatro de largo entre os rios Toropi-miri, e o segundo Yaguari ${ }^{23}$, e terminada pelo Sul com a Serra, e seus mattos, á qual atravessa a estrada pela antiga Picada chamada de S. Tiago"24.

Como bem observado por Saint-Hilaire, eram apenas duas as passagens existentes na Serra Geral para acesso às antigas Reduções Jesuíticas e ambas "muito ruins": a de São Martinho, situada a leste, e a da Picada de São Tiago, a

${ }^{23}$ José de Saldanha assim chama o rio Jaguari, por ter anteriormente descrito outro "Yaguari", o atual Pirajaçá, afluente do "Ybicuy-guasú"(atual rio Santa Maria). Afluente da margem direita do rio Santa Maria, o Pirajaçá corre de leste para oeste, ao sul de São Gabriel.

${ }^{24}$ SALDANHA, J. de. Op. cit., p. 293. 
oeste. Esta última, aberta pelos "Miguelistas" ${ }^{25}$ para trazer o gado de sua "longínqua estancia do Vacca-cahy Guaçú" ${ }^{26}$, foi a utilizada por Saint-Hilaire e José de Saldanha, como visto anteriormente.

Em documentos ainda mais antigos, como no diário ${ }^{27}$ do padre Tadeo Xavier Henis, também se encontram referências à Estância de Santiago, sempre coincidentes com o posicionamento geográfico implícito nos textos anteriormente analisados. Foi nessa "Capilla de São Tiago", aliás, que uns vinte "Luisistas"28 sobreviventes da Guerra Guaranítica, acompanhados de soldados de outros povos e de padres jesuítas, fizeram suas orações e "cantaron tambien um responso por los que habian muerto en la pelea", conforme registro no item 93 do diário do Padre Henis ${ }^{29}$.

\section{CONCLUSÕES}

A moderna cidade de Santiago não pode assentar suas raízes na capela jesuítica de mesmo nome, pelo simples fato de que ela foi erguida entre os rios Jaguari e Toropi. Em nenhum relato de antigo cronista, bem como na copiosa bibliografia deixada pelos jesuítas, se encontra um único indício sobre a existência de uma "Capela de Santiago", erigida em terras do atual município de mesmo nome.

Independentemente da grafia usada nos documentos e textos históricos (S. Tiago, São

${ }^{25}$ Relativo ao povo da Redução de São Miguel Arcanjo.

26 TESCHAUER, C. Historia do Rio Grande do Sul dos dous primeiros seculos. Porto Alegre: Selbach, 1921. v. 2. p. $270-271$.

${ }^{27}$ HENIS, T.X. Diario Historico de la rebelion y guerra de los pueblos guaranis, situados en la costa oriental del rio Uruguay, del año 1754. Escrita originalmente em latim, esta valiosa obra está disponível online, em versão castelhana e com texto integral, no site: www.gutenberg.net. O texto integral consta, ainda, entre os documentos do $5^{\circ}$ volume da famosa "Colección Pedro de Angelis" (Buenos Aires, Editorial Plus Ultra, 1970. p. 449-577).

${ }^{28}$ Relativo ao povo jesuítico de São Luiz Gonzaga.

${ }^{29}$ HENIS, T.X. Op. cit., p. 550-551.
Tiago, S. Thiago, Sant'Iago, Santo Iago, Santiago), não resta a menor dúvida sobre a localização dessa histórica capela: ela ficava em terras de Jarí e não no município de Santiago.

\section{REFERÊNCIAS BIBLIOGRÁFICAS}

CONSTANTINO, N. S. de. Santiago - RS; da concepção à maturidade em compasso brasileiro. Porto Alegre: Martins Livreiro, 1984. 147p.

HENIS, T.X. Diario historico de la rebelion y guerra de los pueblos guaranis, situados en la costa oriental del rio Uruguay, del año 1754. Buenos Aires: Editorial Plus Ultra, 1970. v. 5. p. 449577.

ISABELLE, A. Viagem ao Rio Grande do Sul. Porto Alegre: Museu "Julio de Castilhos", Secção do Arquivo Histórico, 1946. 160 p. (Tradução e notas de Dante de Laytano).

ISABELLE, A. Viagem ao Rio da Prata e ao Rio Grande do Sul. Rio de Janeiro: Livraria Editora Zelio Valverde S.A., 1949. 345 p. (Tradução e nota sobre o autor, de Theodomiro Tostes).

POZO, G. Um pouco da história de Santiago. Santiago: s. ed., 1982.90 p.

PORTO, A. História das Missões Orientais do Uruguai. Porto Alegre: Livraria Selbach, 1954. v. 1. $434 \mathrm{p}$.

SAINT-HILAIRE, A. de. Viagem ao Rio Grande do Sul. Porto Alegre: Estante Rio-Grandense União de Seguros - ERUS; Martins Livreiro, 1987. 496 p.

SALDANHA, J. de. Diário Resumido e Histórico. Anais da Biblioteca Nacional, Rio de Janeiro, v. 51, p. 137-301, 1938.

SILVEIRA, H.J.V. da. As Missões Orientais e seus antigos domínios. Porto Alegre: Typographia da Livraria Universal de Carlos Echenique, 1909. $702 \mathrm{p}$.

SIMÕES, A.A. Santiago, sua terra, sua gente. Porto Alegre: Martins Livreiro, 1989. 196 p.

SOUTHEY, R. História do Brasil. Belo Horizonte: Ed. Itatiaia; São Paulo: Ed. da Universidade de São Paulo, 1981. v. 3. 476 p.

TESCHAUER, C. Historia do Rio Grande do Sul dos dous primeiros seculos. Porto Alegre: Selbach, 1921. 446 p. 